Figure1. Modification of Treg (A) and Th17 (B) populations at baseline and after one month of Tofacitinib treatment in RA patients.
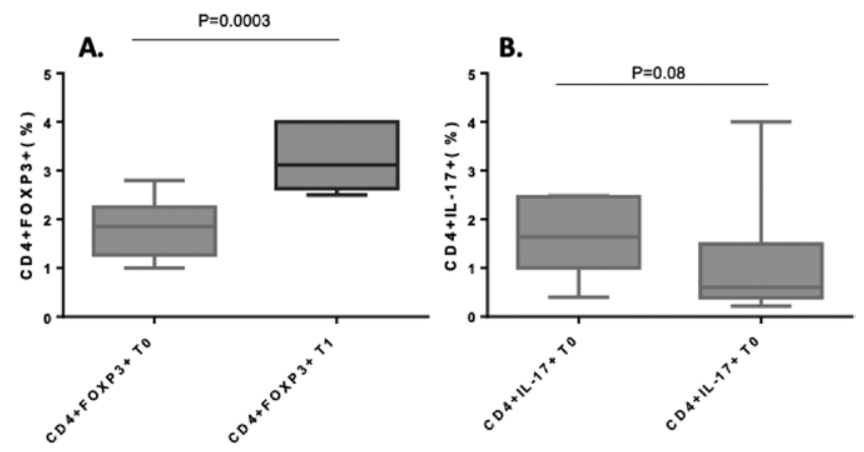

Disclosure of Interests: viviana antonella pacucci: None declared, cristiana barbati: None declared, Francesca Romana Spinelli Grant/research support from: Pfizer, Speakers bureau: Lilly, BMS, Celgene, Fulvia Ceccarelli: None declared, Silvia Mancuso: None declared, Cristina Garufi: None declared, cristiano alessandri Grant/research support from: Pfizer, fabrizio conti Speakers bureau: BMS, Lilly, Abbvie, Pfizer, Sanofi

DOI: 10.1136/annrheumdis-2020-eular.4403

\section{AB0356 TARGETING THE RHEUMATOID ARTHRITIS SYNOVIAL FIBROBLAST VIA CYCLIN DEPENDENT KINASE INHIBITION (TRAFIC): A PHASE 1B STUDY TO DETERMINE THE MAXIMUM TOLERATED DOSE OF SELICICLIB FOR REPURPOSING IN RHEUMATOID ARTHRITIS}

A. Pratt ${ }^{1}$, S. Siebert ${ }^{2}$, M. Cole ${ }^{3}$, D. Stocken ${ }^{4}$, S. Kelly ${ }^{5}$, M. Shaikh 6 , A. Cranston ${ }^{7}$, M. Morton ${ }^{7}$, J. Walker ${ }^{7}$, S. Frame ${ }^{8}$, W. F. Ng ${ }^{1}$, C. Buckley ${ }^{9}$, I. Mcinnes ${ }^{2}$, A. Filer ${ }^{9}$, J. D. Isaacs ${ }^{1} .{ }^{1}$ Newcastle University Translational and Clinical Research Institute, Newcastle upon Tyne, United Kingdom; ${ }^{2}$ Institute of Infection, Immunity and Inflammation, University of Glasgow, Glasgow, United Kingdom; ${ }^{3}$ Newcastle University Population Health Sciences Institute, Newcastle upon Tyne, United Kingdom; ${ }^{4}$ Leeds Institute of Clinical Trials Research, University of Leeds, Leeds, United Kingdom; ${ }^{5}$ Department of Rheumatology, Barts Health NHS Trust, London, United Kingdom; ${ }^{6}$ Department of Rheumatology, James Cook University Hospital, Middlesbrough, United Kingdom; ${ }^{7}$ Newcastle University Clinical Trials Unit, Newcastle upon Tyne, United Kingdom; ${ }^{8} \mathrm{Cyclacel}$ Ltd., Dundee, United Kingdom; ${ }^{9}$ Institute for Inflammation and Ageing, University of Birmingham, Birmingham, United Kingdom

Background: Current rheumatoid arthritis (RA) therapeutics target immune inflammation and are subject to ceiling effects, with non-response observed in a third of recipients together with low remission rates. Synovial fibroblasts (SFs) are stromal cells not yet targeted in RA, whose hyperplastic and proliferative properties drive inflammation and tissue destruction. Seliciclib (R-roscovitine) is an orally available cyclin-dependent kinase (CDK) inhibitor that suppresses SF proliferation and ameliorates inflammatory arthritis in rodents.

Objectives: To determine the maximum tolerated dose (MTD) of seliciclib in patients with active RA despite anti-TNF, with or without background conventional disease modifying anti-rheumatic drugs (CDMARDs). Safety and pharmacokinetics (PK) were also evaluated.

Methods: A restricted, one-stage Bayesian continual reassessment method (CRM) determined MTD based on a target dose-limiting toxicity (DLT) probability of $35 \%$. RA patients (DAS28 $\geq 3.2$ ) were recruited sequentially to cohorts of 3 subjects each. Cohort 1 received $400 \mathrm{mg}$ seliciclib daily for 4 consecutive days each week for 4 weeks, added to existing therapy. Each subsequent cohort received a dose determined by the toxicity-based CRM algorithm, calculated upon conclusion of the previous cohort. Safety was assessed through adverse event (AE) monitoring. Associations with relevant PK parameters were sought. Results: 15 anti-TNF recipients were enrolled, 10 of whom were also taking cDMARDs (median DAS28 4.9). Application of the CRM algorithm prompted one dose increment during the study (to $600 \mathrm{mg}$ for cohort 2), but reversion to $400 \mathrm{mg}$ for subsequent cohorts (Figure 1A). After treatment of 5 cohorts, $400 \mathrm{mg}$ was determined the MTD, with a DLT probability of 0.35 (Cl 0.18-0.52; Figure 1B). 6 patients experienced DLTs, of which two were classified as serious AEs (SAEs) in keeping with the safety profile of seliciclib; these are summarised in Table 1. Of $43 / 65$ total AEs reported at any dose that did not contribute to a DLT, 26 were possibly, probably or definitely related to seliciclib; 19 of these 26 were mild, 7 moderate and none severe. The most frequent AE was mild nausea. No relationship of safety and/or tolerability with concomitant CDMARD use or PK was seen.

Table 1. AOutcome of contributory AEs/SAE at close of follow-up. ${ }^{\text {BSAEs }}$ classified as 'expected'. DLT: dose limiting toxicity; $N+V$ : nausea, vomiting.

\begin{tabular}{|c|c|c|c|c|c|c|}
\hline DLT & $\begin{array}{c}\text { Seliciclib } \\
\text { dose }(\mathrm{mg})\end{array}$ & $\begin{array}{c}\text { Doses } \\
\text { received }\end{array}$ & $\begin{array}{c}\text { Contributing } \\
\text { AEs }\end{array}$ & $\begin{array}{l}\text { Contributing } \\
\text { SAEs }\end{array}$ & Description & Outcome $^{A}$ \\
\hline 1 & 400 & 8 & 3 & 0 & $\begin{array}{l}\text { Constipation, } \\
\mathrm{N}+\mathrm{V} \text {, liver injury; } \\
\text { fatigue. }\end{array}$ & Resolved \\
\hline 2 & 600 & 4 & 3 & 0 & $\begin{array}{c}\text { Constipation, } \\
\mathrm{N}+\mathrm{V} \text {. }\end{array}$ & Resolved \\
\hline 3 & 600 & 1 & 0 & $1^{\mathrm{B}}$ & $\begin{array}{l}\text { Fever, } N+V \text {, renal } \\
\text { injury. }\end{array}$ & | Resolved \\
\hline 4 & 400 & 8 & 3 & $1^{\mathrm{B}}$ & $\begin{array}{l}\text { Constipation, } \\
\mathrm{N}+\mathrm{V} \text {, jaundice, } \\
\text { liver injury. }\end{array}$ & Resolved \\
\hline 5 & 400 & 8 & 4 & 0 & $\begin{array}{l}\text { Fever, dizziness, } \\
\text { liver injury. }\end{array}$ & Resolved \\
\hline 6 & 400 & 8 & 9 & 0 & $\begin{array}{l}\text { Dizziness, } N+V \text {, } \\
\text { liver injury, biliru- } \\
\text { bin rise. }\end{array}$ & $\begin{array}{l}\text { Persistent } \\
\text { AST rise }\end{array}$ \\
\hline
\end{tabular}

Conclusion: The MTD of seliciclib has been defined for RA. No unexpected safety concerns were identified to preclude ongoing evaluation in patients, which focuses on clinical, radiological and biological indicators of efficacy.
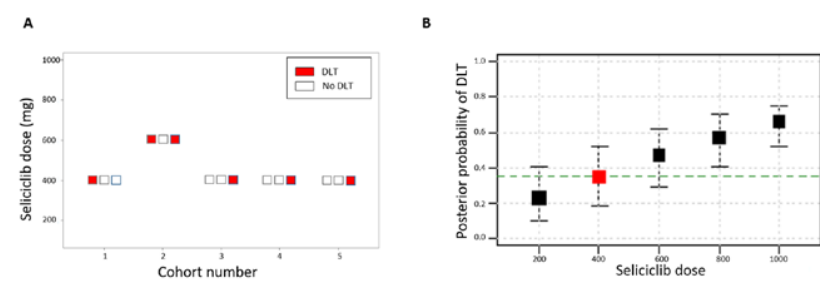

Figure 1. A. Dose limiting toxicity (DLT) occurrence by cohort and dose level (DLTs shown in red). B. Bayesian posterior probability of DLT at each dose level (with 90\% confidence interval) following completion of cohort 5. Red point indicates value closest to target of 0.35 , and hence maximum tolerated dose (MTD).

Disclosure of Interests: Arthur Pratt Grant/research support from: Pfizer, GlaxoSmithKlein, Stefan Siebert Grant/research support from: BMS, Boehringer Ingelheim, Celgene, GlaxoSmithKline, Janssen, Novartis, Pfizer, UCB, Consultant of: AbbVie, Boehringer Ingelheim, Janssen, Novartis, Pfizer, UCB, Speakers bureau: AbbVie, Celgene, Janssen, Novartis, Michael Cole: None declared, Deborah Stocken: None declared, Stephen Kelly: None declared, Muddassir Shaikh: None declared, Amy Cranston: None declared, Miranda Morton: None declared, Jennifer Walker: None declared, Sheelagh Frame Employee of: Cyclacel Ltd., Wan-fai Ng: None declared, Chris Buckley Consultant of: Janssen, Pfizer, GSK, Galapagos, Gillead, lain McInnes Grant/research support from: Bristol-Myers Squibb, Celgene, Eli Lilly and Company, Janssen, and UCB, Consultant of: AbbVie, Bristol-Myers Squibb, Celgene, Eli Lilly and Company, Gilead, Janssen, Novartis, Pfizer, and UCB, Andrew Filer: None declared, John D Isaacs Consultant of: AbbVie, Bristol-Myers Squibb, Eli Lilly, Gilead, Janssen, Merck, Pfizer, Roche DOI: 10.1136/annrheumdis-2020-eular.2443

\section{AB0357 USE OF TOFACITINIB AND REASONS FOR DISCONTINUATION IN CLINICAL PRACTICE}

C. Y. Soleto ${ }^{1}$, B. Serrano Benavente ${ }^{2}$, L. A. Torrens $\mathrm{Cid}^{2}$, J. Martínez-Barrio ${ }^{3}$, J. Molina Collada ${ }^{2}$, J. Rivera ${ }^{2}$, T. González ${ }^{2}$, I. Monteagudo ${ }^{2}$, C. Gonzalez ${ }^{3}$, I. Castrejon ${ }^{3}$, J. M. Alvaro-Gracia ${ }^{3} .{ }^{1}$ Hospital General Universitario Gregorio Maranon, Rheumatology, Madrid, Spain; ${ }^{1}$ Hospital General Universitario Gregorio Maranon, Rheumatology, Madrid, Spain; ${ }^{3}$ Hospital General Universitario Gregorio Maranon, Madrid, Spain

Background: Tofacitinib is an oral JAK 1 and 3 inhibitor for the treatment of moderate to severe active rheumatoid arthritis (RA) or psoriatic arthritis (PsA) in adults with inadequate response or intolerant to one or more conventional disease-modifying antirheumatic drugs (cDMARDs). Since its approval by the European Medicines Agency (EMA), there is limited data about its use in daily practice in Europe.

Objectives: To describe rates and reasons for discontinuation of Tofacitinib in patients with RA and other inflammatory conditions

Methods: We identified patients with a prescription for tofacitinib at our academic center from January 2017 to January 2020. Patients were treated according to their rheumatologist evaluation following standards of care. The following variables were retrospectively collected from the electronic 